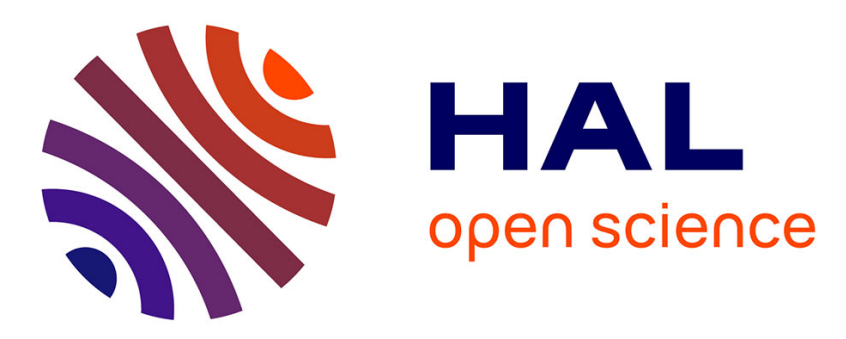

\title{
Influence of polysaccharides on cement hydration
}

Arnaud Peschard, Alexandre Govin, Emmanuel Fredon, Philippe Grosseau, Gilles Fantozzi

\section{To cite this version:}

Arnaud Peschard, Alexandre Govin, Emmanuel Fredon, Philippe Grosseau, Gilles Fantozzi. Influence of polysaccharides on cement hydration. Euroceramics VIII, 2004, France. pp.2141. hal-00125020

\section{HAL Id: hal-00125020 \\ https://hal.science/hal-00125020}

Submitted on 17 Jan 2007

HAL is a multi-disciplinary open access archive for the deposit and dissemination of scientific research documents, whether they are published or not. The documents may come from teaching and research institutions in France or abroad, or from public or private research centers.
L'archive ouverte pluridisciplinaire HAL, est destinée au dépôt et à la diffusion de documents scientifiques de niveau recherche, publiés ou non, émanant des établissements d'enseignement et de recherche français ou étrangers, des laboratoires publics ou privés. 


\title{
Influence of polysaccharides on cement hydration
}

\author{
Peschard A. (1), Govin A. (1), Fredon E. (1), Grosseau P. (1), FAntozzi G. (2)
}

(1) ENSM-SE SPIN Division (Chemical Engineering), 158 cours Fauriel, 42023 Saint Etienne Cedex 02, France

(2) INSA-Lyon (GEMPPM), 20 avenue Albert Einstein, 69621 Villeurbanne Cedex, France

\begin{abstract}
This paper is about the influence of polysaccharides on cement hydration. Three polysaccharides were studied: a cellulose ether (CE), a starch ether (SE) and a dextrin (YD). In a concentrated media as well as in a dilute media, admixture CE only revealed a slight effect on cement hydration. Portlandite and ettringite formation and gypsum consumption were slowed down by SE adjunction. Admixture YD induced an acceleration of ettringite formation as well as gypsum consumption whereas portiandite formation was blocked by this compound.
\end{abstract}

\section{KEYWORDS :}

Cement hydration ; organic admixtures ; polysaccharides.

\section{INTRODUCTION}

Organic admixtures have been extensively used in concrete and mortars formula during the past twenty years. The need of building materials with more and more technical properties has generalized the use of this kind of admixtures. Polysaccharides are bio-polymers extracted from plants. They are used as cement admixtures and they provide several advantageous properties to mortars. They particularly improve water retention, workability and durability of coatings. The understanding of interaction mechanisms between cement and polysaccharides is still incomplete. Most studies were devoted to the interaction of monosaccharides with cement or single phases present in cement [1-4]. The aim of this study is to elucidate interaction mechanisms between polysaccharides and cement in order to rationalize and optimize the use of these compounds in mortars formula.

\section{EXPERIMENTAL PROCEDURE}

\section{Raw materials}

Several kinds of polysaccharides have been selected: a cellulose ether (CE), a starch ether (SE), and a yellow dextrin (YD). The main variations in these compounds lay in the nature, degree of substitution, and degree of polymerization. Two types of portland cements were used, a white one $\left(\mathrm{C}_{1}\right)$ and a grey one $\left(\mathrm{C}_{2}\right)$, their main differences lay in $\mathrm{C}_{3} \mathrm{~A}$ and alcali-content. $\mathrm{C}_{3} \mathrm{~A}$ content in $\mathrm{C}_{1}$ was 5 times higher.

\section{Methods of investigation}

In most experiences, polysaccharides to cement weight ratio $(\mathrm{P} / \mathrm{C})$ was $0.5 \%$. Water to cement ratio (W/C) was approximately 0.3 . Samples were washed with anhydrous alcohol to stop hydration. Thermal analysis on hydrated cement was performed on a Setaram TG-DSC 111. Experiments were conducted with a heating rate of $10^{\circ} \mathrm{C} / \mathrm{min}$ from $20^{\circ} \mathrm{C}$ up to $800^{\circ} \mathrm{C}$ under a dynamic Argon atmosphere on a 25mg sample approximately. The advancement of cement hydration was followed by electric conductivity on dilute suspensions with a liquid to solid ratio equal to 20. 


\section{RESUlts}

\section{Analysis of cement pastes}

Quantifies of ettringite and gypsum were obtained by deconvolution of decomposition peaks observed on DTG curves. These quantifies can be obtained before 4 hours of hydration. After this delay decomposition peaks of $\mathrm{CSH}$ and ettringite overlapped. Portlandite quantity $(\% \mathrm{CH})$ was determined by the formula:

$$
\% C H=W L_{C H}(\%) x \frac{M W_{C H}}{M W_{H}}
$$

Equation

WLCH corresponds to weight loss of portlandite in percent on TG curves, $\mathrm{MW}_{\mathrm{CH}}$ to molar weight of portlandite and $\mathrm{M}_{\mathrm{H}}$ to molar weight of water. Admixture YD accelerated ettringite formation whereas SE retarded its formation (Figure 1a). Admixture $\mathrm{CE}$ had no significant effect on ettringite formation. These results were in good accordance with the evolution of gypsum consumption. $\mathrm{C}_{1}+\mathrm{YD}$ formula exhibited an accelerated gypsum consumption effect whereas it was slowed down for $\mathrm{C}_{1}+\mathrm{SE}$ (Figure 1b).

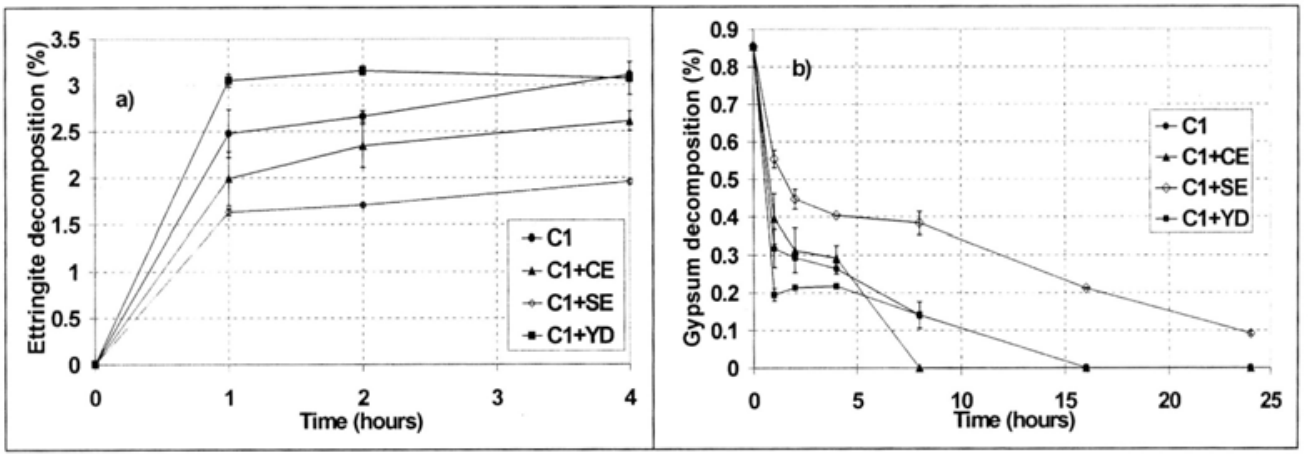

Figure 1: Evolution of (a) ettringite formation, (b) gypsum consumption depending

on the nature of the polysaccharide added

As far as $\mathrm{CH}$ formation is concerned (Figure 2), $\mathrm{CE}$ displayed a slight effect. Admixture YD blocked portlandite formation during 8 hours after what the formation rate was similar to that of pure cement. The admixture SE slowed down portlandite formation during 24 hours of hydration.

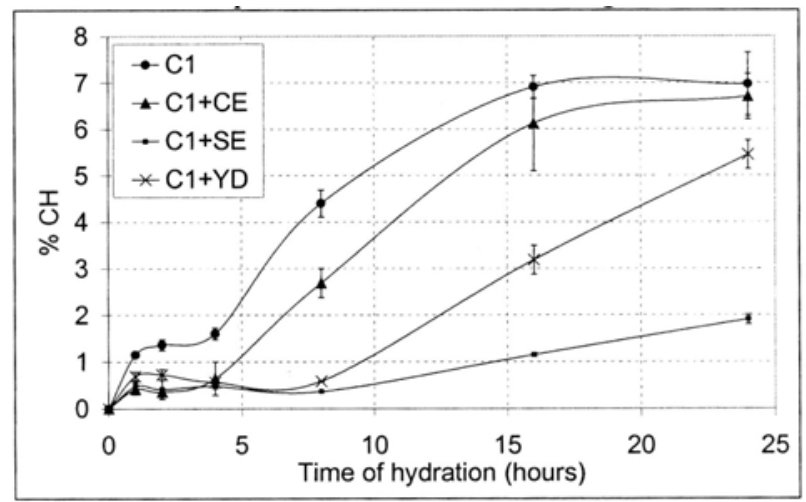

Figure 2: $\quad$ Evolution of portlandite formation vs polysaccharide added

In addition, adjunction of $\mathrm{YD}$ on $\mathrm{C}_{2}$ stabilised ettringite phase and completely inhibited $\mathrm{CH}$ formation. An amount of $3 \%$ of $\mathrm{YD}$ to $\mathrm{C}_{1}$ was necessary to produce a 
similar effect. Hence the $\mathrm{C}_{3} \mathrm{~A}$ content of cement seemed to be an important parameter. For a given set-retardation the higher the $\mathrm{C}_{3} \mathrm{~A}$ content was, the higher, the $\mathrm{P} / \mathrm{C}$ ratio had to be. This result was in good accordance with RAMACHANDRAN [5]. $\mathrm{C}_{3} \mathrm{~A}$ phase seemed to inhibit set retarding effect of admixtures on $\mathrm{C}_{3} \mathrm{~S}$ phase.

\section{Effect of poly saccharides on cement dilute suspensions}

In order to elucidate cement-polysaccharides interactions, a study was carried out on cement suspensions. According to COMPARET et al [6], conductimetric curve of a neat cement exhibits first a fast increase of conductivity related to its rapid dissolution. Then the first change of slope corresponds to first hydrate nucleation. The subsequent moderate increase of conductivity is linked to a free crystal growth and then to a growth limited by diffusion. The maximum of conductivity and the rapid decrease correspond to portlandite precipitation. As shown on Figure 3a, the evolution of conductivity was dependent on the nature of the polysaccharide introduced.

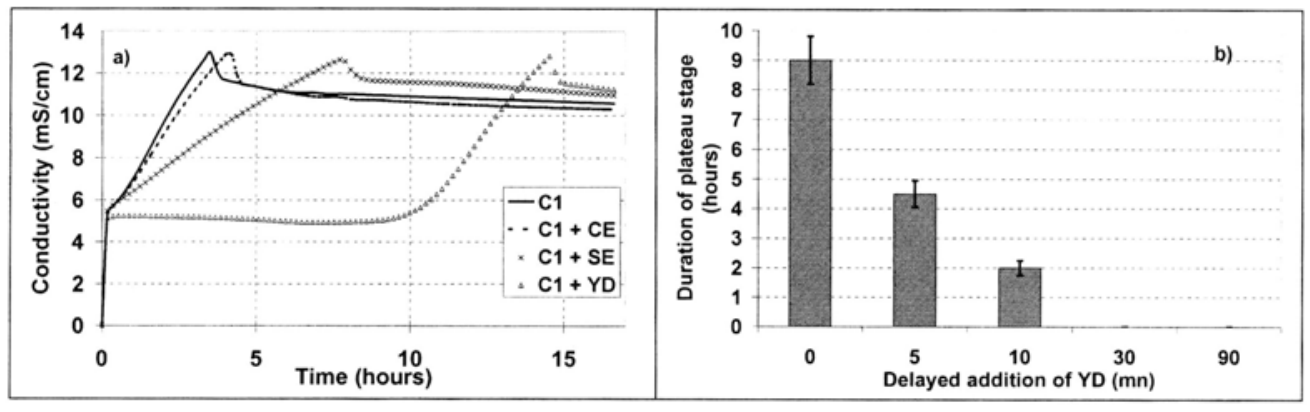

Figure 3: (a) Conductimetric curves of $\mathrm{C}_{1}$ suspensions vs nature of polysaccharide

(b) Duration of plateau stage for a delayed addition of YD

The evolution of conductivity was also dependent on the time at which the polysaccharide was introduced (Figure $3 b$ ). For a YD/ C ratio equal to $0.5 \%$, the more the adjunction was delayed, the more the effect was reduced. A delayed addition needed a higher quantity of YD to block the system. It has let us to consider that action of YD on cement must occur by adsorption on hydrates. If growth mechanism has already begun, adjunction of YD was not sufficient anymore to disturb the process.

One explanation of the different effects of polysaccharides on cement hydration could be linked to their behaviour in alkali-media. Hence polysaccharides were dispersed in calcium hydroxide to reproduce the effect of cement medium on admixtures. Solids residues were analysed by infra-red spectrometry. Polysaccharides with low molecular weight depolymerize and create sugar acids and shorter polysaccharides comprising a carboxylate group [7,8]. The polysaccharides studied, with a high molecular weight, were more stable in alkali medium. A peak at $1590 \mathrm{~cm}^{-1}$ attributed to vibration frequency of carboxylate groups [9] for admixture YD appeared on infrared spectra. This peak was not observed for admixtures CE and SE. It has let us to consider that polysaccharide decomposition was a key parameter concerning its effect on cement. Some studies have shown that sugar acids (with carboxylate function) were more efficient set retarders than sugars [10].

\section{CONCLUSIONS}

Cement composition and especially the amount of $\mathrm{C}_{3} \mathrm{~A}$ in cement were important parameters to determine the quantity of polysaccharide that should be introduced. 
Study on cement paste allowed to determine specifically the quantity of hydrates formed. Depending on the polysaccharide introduced a change of formation rate of ettringite and portlandite took place. The effect of polysaccharides on cement hydration was strongly dependant on their nature, and on their molecular weight. Admixture YD had to be added before crystal growth, otherwise its efficiency as a set retarding agent is low. A complementary study on selected starch derivatives could clarify the singular effect of YD. An identification of polysaccharide degradation products could give valuable information on the active molecule responsible for set retardation. These results will be completed by a mechanical study on the effect of polysaccharides on adhesion of wall coatings.

\section{REFERENCES}

[1] G. Bruere: Nature, V0l 212 (1966), p. 502

[2] H.M. J ennings, H. Taleb, G. Frohnsdorff, J.R. Clifton: in Proceedings of the 8th International Congress on the Chemisty of Cement VOI III (1986). Rio de J aneiro, p. 239

[3] K. Luke, G. Luke: Advances in Cement Research, Vol $12 \mathrm{~N}^{\circ} 1$, (2000), p. 9

[4] N.L. Thomas, J.D. Birchall: Cement \& Concrete Research, Vol 13, (1983), p. 830

[5] V.S.Ramachandran: Cement \& Concrete Research, Vol 2, (1972), p. 179

[6) C. Comparet, A. Nonat, S. Pourchet, J.P. Guicuero, E. Gartner, M. Mosquet: in Proceeding of the Sixth CANMET/ACI International Conference on Superplasticizers and others Chemical Admixtures in Concrete, (1997), Rome, p. 61

(7] R.L. Whistler, J.N. Bemiller. Advances in Carbohydrate Chemistry and Biochemistry, Vol 13 (1958), p. 289

[8] C.J . Knill, J .F. Kennedy: Carbohydrate Polymers, V0l 5 Nº3, (2003), p. 281

[9] I.M. Demiate, N. Dupuy, J.P. Huvenne, M.P. Cereda, G. Wosiacki: Carbohydrate Polymers, Vol 42, (2000), p. 149

[10] N.B. Singh: Cement and Concrete Research, V0l 6 (1976), p. 455 